\title{
Análisis "coste-beneficio" y "coste-eficiencia" de la Huella Hídrica en España
}

\author{
José Antonio SoTe LO NAvALPOTr O \\ jasotelo@ghis.ucm.es \\ María SoTeLO Pér ez \\ maria_sotelo_perez@hotmail.com \\ Fernando GAr CíA Qu Ir OGA \\ nancht@hotmail.com \\ Grupo de Investigación uCM: Desarrollo y Gestión Ambiental del Territorio*
}

recibido: 6 de Septiembre de 2011

enviado a evaluar: 7 de Septiembre de 2011

Aceptado: 5 de Octubre de 2011

\section{RESUMEN}

Cada vez más necesitamos maneras de asegurar patrones de desarrollo que sean sustentables, es decir, que sean ambiental, social y económicamente apropiados para nosotros y para las generaciones venideras. Los indicadores de desarrollo sustentable son una herramienta que permitiría aproximarnos al concepto de sustentabilidad, apoyando la manera en que se toman las decisiones. en e spaña existen pocas experiencias sobre el tema. e ste artículo presenta el trabajo realizado para desarrollar indicadores de desarrollo sustentable. A lo largo del presente estudio se muestra la importancia del análisis "coste-beneficio" y "coste-eficiencia" en la valoración de la Huella Hídrica de e spaña.

Palabras clave: Indicadores, desarrollo sustentable, desarrollo económico regional, Huella Hídrica, españa, Coste-Beneficio.

\section{Cost-benefit and cost-efficiency analysis of the water footprint in Spain}

\begin{abstract}
We are increasingly needing ways to secure patterns of development that be sustainable, that is, environmentally, socially and economically appropriate for us and for future generations. Sustainability indicators are a promising tool that would allow us to "land" the concept, supporting the way in which decisions are made. In Spain there are few experiences on the subject. This paper presents the work carried out to develop sustainability indicators. Throughout the present study shows the importance of analysis of "cost-benefit" and "cost efficency" in the assessment of the water footprint of Spain.
\end{abstract}

Keywords: Indicators, Sustainable Development, regional economic development. Water Footprint, Spain, Cost-Benefit.

* Proyecto CICYT: CGL2007-63779 


\title{
Analyse "coûts-avantages" et "coûts-efficacité" de l'empreinte hydrique de l'Espagne
}

\begin{abstract}
RESUMÉ
De plus en plus, nous avons besoin de façons pour assurer des modes de développement qui soient durables, c'est-à-dire, qui soient du point de vue environnemental, social et économique appropriés à nous y aux générations futures. Les indicateurs de développement durable sont un outil qui permettra notre approche au concept de durabilité, tout en appuyant la manière dont on prend les décisions. En Espagne il y a peu $\mathrm{d}$ 'expériences dans ce domaine. Dans cet article on présente le travail réalisé pour développer des indicateurs de développement durable. Cet étude montre l'importance de l'analyse "coûts-avantages" et "coûtsefficacité" dans la valorisation de l'Empreinte Hydrique en Espagne
\end{abstract}

Mots clé: Indicateurs, développement durable, développement économique régional, Empreinte Hydrique, Espagne, Coûts-Avantages

\section{INTRODUCCIÓN:}

Una primera aproximación conceptual nos acerca a la idea de que el término coste en la literatura económica se emplea para referirse a todo esfuerzo, sacrificio o pérdida que sea susceptible de valoración. En un entorno de recursos económicos escasos y susceptibles de usos alternativos, cualquier acción que implique el empleo de un recurso supone incurrir en un coste, al margen de que tal empleo exija o no como condición previa el pago de una contraprestación monetaria, es decir, de un precio. Así, el concepto de coste entendido en sentido estricto lleva implícita la noción de coste de oportunidad (es decir, el coste de utilizar los recursos para una determinada finalidad medido por el beneficio a que se renuncia al no utilizarlos en su mejor uso alternativo).

En el contexto de un mercado teórico perfectamente competitivo el coste de oportunidad del empleo de cualquier recurso viene dado por su precio de mercado, dado que el precio refleja exactamente en tal caso el valor marginal del recurso, no cabiendo ningún uso alternativo en el que se pueda derivar un valor superior (ya que los mejores usos potenciales ya están cubiertos). El problema surge en la realidad porque tales mercados perfectamente competitivos no existen (de tal modo que los precios no reflejan el verdadero coste de oportunidad de los recursos) y porque, para algunos recursos, simplemente no existe mercado (indudablemente, esta realidad económica cobra relativa importancia cuando sus consecuencias se materializan en un determinado espacio o territorio).

Y es que en las últimas décadas, tanto los métodos como las reglas y los propios marcos del proceso de decisiones en materia de medio ambiente, han ido evolucionando desde los enfoques específicos de la eficiencia económica hasta los objetivos inherentes al denominado desarrollo sostenible. De esta forma, cada vez han adquirido mayor importancia los denominados "métodos alternativos", que ofrecen un 
conjunto de escenarios que incluyen la evaluación y la ponderación de las ganancias y pérdidas relacionadas con cuestiones y criterios varios. La valoración de los beneficios ambientales derivados de la protección de un espacio natural mediante cualquier instrumento eficaz de protección, y normalmente por medio de la aprobación y puesta en vigor de normas jurídicas, cualesquiera que sean los instrumentos de protección que ellas introduzcan (instrumentos "regulatorios", económicos, de mercado o de esta triple categoría), por virtud del poder de imperio de las administraciones públicas', se hace precisa para introducir mayores grados de racionalidad - reduciendo, asimismo, el reinado de la discrecionalidad - en el ámbito de las políticas de control de la calidad ambiental, de las políticas de desarrollo rural sostenible e, incluso, en el de la política presupuestaria de dichas administraciones públicas.

La relativamente moderna aparición de las técnicas de valoración de los beneficios ambientales y su propia diversidad, reside en la dificultad de aproximar cuantitativamente, y expresar en unidades monetarias el importe de la mejora que la sociedad en su conjunto obtiene del incremento de la protección ambiental sobre estos espacios naturales, habida cuenta de que los espacios objeto de la política de intervención proporcionan bienes y servicios públicos. La mayor parte de estos bienes y servicios públicos, puros o mixtos, además se extiende hacia el futuro y, al tratar de valorarlos, el investigador se encuentra enfrentado al problema adicional de que los mismos abarcan un horizonte temporal indeterminado pero amplio, por lo que debe resolver además, problemas relacionados con la determinación de la tasa de descuento aplicable, adecuada al flujo de los mismos en un horizonte temporal indeterminado.

Pero es que dicha valoración es imprescindible en estos momentos en los que se ha detectado en materia de espacios naturales que su ausencia, como sucede con la mayor parte de los bienes y servicios públicos, ha favorecido su sobreexplotación, o uso inadecuado y, finalmente, el deterioro de los mismos desde todas sus múltiples perspectivas(hábitat, aves, fauna, flora, suelos, paisajes, etc.), al menos en muchas ocasiones empíricamente comprobadas. Pocos de estos espacios naturales han tenido acceso al mercado, a ese mecanismo de asignación eficiente en condiciones muy determinadas, bien por su misma imposibilidad de existir, bien por su incorrecto funcionamiento al tratarse de bienes de libre acceso, no sometidos al principio de exclusión y no rivales en el consumo, en mayor o menor medida; la ausencia del mercado o su defectuoso funcionamiento es, precisamente, una de las causas de dicha sobreexplotación y uno de los factores que, simultáneamente, ha impedido la apreciación de su progresivo deterioro a lo largo del tiempo, reductor asimismo de su capacidad de generar servicios valiosos para la colectividad en su conjunto en el presente y en el futuro.

Los modelos de valoración de los flujos de servicios que se derivan de una determinada política de protección de la naturaleza, requieren normalmente:

- Partir de una valoración de la calidad del recurso ambiental sobre el que va a producirse la actuación pública(Q). Este valor, imposible de identificar con el concepto precio- habida cuenta de que sobre los recursos ambientales no se constituye siquiera el mercado -, suele relacionarse con algunas medidas de su valor(P) derivada de las respuestas de los agentes privados $-\mathrm{R}(\mathrm{P})$-. Esta rela- 
ción $(\mathrm{R})$, recoge esencialmente la variedad de procesos físicos y biológicos que se reúnen en su entorno.

$$
\begin{aligned}
& \mathrm{Q}=\mathrm{Q}(\mathrm{P}) \\
& \mathrm{Q}=\mathrm{Q}[\mathrm{P}, \mathrm{R}(\mathrm{P})]
\end{aligned}
$$

- Y, tratar de valorar en términos monetarios los flujos de servicios que se derivan de dicho recurso ambiental(V), el cual suele considerarse como una función del uso que la sociedad hace de recursos ambientales $(\mathrm{X})$

$$
\mathrm{V}=\mathrm{V}(\mathrm{X})
$$

- Sabiendo que X depende, a su vez, de Q(la calidad del recurso) y de todos los inputs de trabajo, capital, tiempo, etc. que introducidos sobre el recurso natural, estarán relacionados con su calidad(Y(Q)).

$$
\mathrm{X}=\mathrm{X}[\mathrm{Q}, \mathrm{Y}(\mathrm{Q})]
$$

- Así pues, puede formalizarse la función de valoración social respecto del recurso natural, sustituyendo en (3), las ecuaciones (2) y (4); de este modo:

$$
\mathrm{V}=\mathrm{f}[\mathrm{P}, \mathrm{R}(\mathrm{Q}), \mathrm{Y}(\mathrm{Q})]
$$

- La ecuación (5) expresa el valor que la sociedad atribuye a dicho recurso natural en concreto, del que se trata. Cuando se genera un cambio en la política de protección del recurso natural, se producirán alteraciones en $\mathrm{V}$, como consecuencia de los cambios introducidos en $\mathrm{P}$ y Q. Por tanto, los Beneficios ambientales de dicho cambio político (B), serán exactamente iguales a la variación de $\mathrm{V}(\mathrm{DifV})$ :

$$
\mathrm{B}=\text { Dif } \mathrm{V}=\mathrm{f}[\mathrm{P} 2, \mathrm{R}(\mathrm{Q} 2), \mathrm{Y}(\mathrm{Q} 2)]-\mathrm{f}[\mathrm{P} 1, \mathrm{R}(\mathrm{Q} 1), \mathrm{Y}(\mathrm{Q} 1)]
$$

Nótese que los subíndices 1 y 2 denotan el estado de la política de regulación ambiental del espacio natural antes y después del cambio protector introducido y los respectivos estados de $\mathrm{P}$ y $\mathrm{Q}$ correspondientes a dichos estados.

Este simple proceso de razonamiento hace comprensible la idea de que el proceso de estimación de los beneficios ambientales de la alteración en las políticas de protección de los espacios naturales implican la previa determinación del valor monetario que el público otorga a los bienes y servicios ambientales que dicho activo genera. La cuestión es cómo determinan dicho valor. Para ello, la ciencia económica proporciona diversos enfoques o métodos de valoración.

\section{EL ANÁLISIS COSTE-BENEFICIO DE LA "HUELLA HÍDRICA" EN ESPAÑA:}

Al realizar el estudio de la "Huella Hídrica" a través del Análisis Coste-Beneficio (ACB) vamos a evaluar monetariamente las corrientes de beneficios y costes que, desde el punto de vista de la sociedad en su conjunto, se asocian con cada una de las alternativas que se estudian. En el presente estudio, atendiendo a la definición económica, el análisis coste-beneficio ha consistido en la estimación y evaluación de los beneficios netos obtenidos de la oferta de "Huella Hídrica" en España, asociados con 
el objetivo principal de hacer frente a la demanda de "Huella Hídrica", desde un punto de vista sostenible económica, ecológica y socialmente

$\mathrm{El}$ análisis coste-beneficio tiene su origen en la necesidad de evaluar en nuestro estudio, el peso global de la escasez del recurso "agua" como fuente principal de subsistencia y de desarrollo. El análisis coste-beneficio cuenta con un sustento teórico muy sólido, constituido por la teoría económica del bienestar (Welfare Economics); de ésta se deriva como uno de los más usados, el criterio de óptimo de Pareto. En este sentido, con el análisis coste-beneficio, lo que se pretende es ver en que medida el impacto, en términos monetarios, de hacer frente a una demanda creciente de "Huella Hídrica", atendiendo a cuestiones de escasez de agua, incide de la manera más homogénea posible sobre el conjunto de los agentes económicos y, por ende, sobre la sociedad.

Cuadro 1.- Diagrama del Análisis de la "Huella Hídrica"

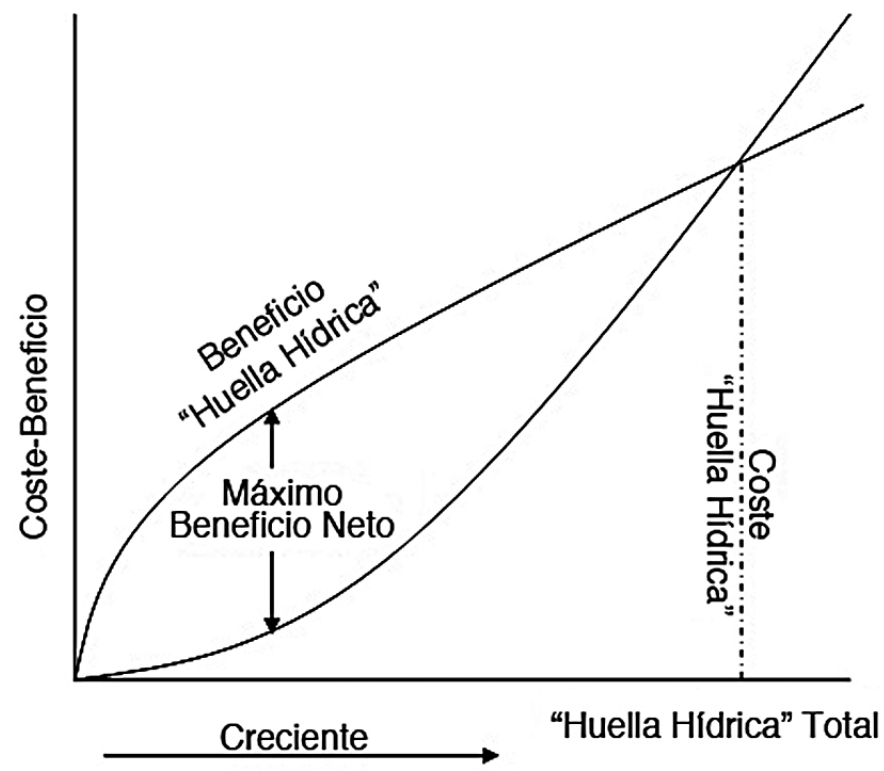

Fuente: Elaboración propia

\subsection{DEFINICIÓN DE COSTE Y BENEFICIO DE LA "HUELLA HÍDRICA"}

Un beneficio (coste) es una ventaja (desventaja) relevante de la clase que sea, que afecta a unos agentes determinados y se produce en unos periodos de tiempo concretos.

Para ello, es necesario cuantificar y valorar correctamente dicha ventaja (desventaja). A su vez, la consideración de un impacto como coste o beneficio depende del ámbito geográfico -en nuestro caso de estudio es España- en el que se evalúa la "Huella Hídrica" y de la función objetivo de que se disponga. Esta muy claro que quién debe decidir si se clasifica un impacto como ventaja o desventaja; las personas 
que reciben el impacto, a través de sus acciones económicas. Una forma simple para identificar un beneficio (coste) consiste en observar si ha aumentado (disminuido) la cantidad de riqueza del sistema, entendiendo riqueza en su sentido más amplio;

Se produce un beneficio (coste) siempre que aumenta (disminuye) la cantidad de riqueza del sistema.

Pero, a la hora de hablar de una realidad tan compleja como es la "Huella Hídrica" en España, no sólo debemos centrarnos en una riqueza monetaria o material, sino que debemos tener en cuenta la cantidad y calidad del recurso hídrico, del impacto que tiene su explotación en el medio natural, sobre la sociedad y sobre la economía española.

De igual modo, si se dispone de una función objetivo que mida el beneficio neto, en las unidades que el decisor haya elegido, la definición de coste y beneficio es inmediata:

Un elemento determinado supone un beneficio (coste) si al aumentar la cantidad de este elemento, la función objetivo aumenta (disminuye) de valor, todo lo demás constante.

Teniendo bien definido lo que significa un óptimo, y disponiendo de una función que mida la distancia entre un punto cualquiera y el óptimo predefinido (o el objetivo), puede definirse un coste o un beneficio:

Un impacto cualquiera es un beneficio (coste) si al aumentar dicho impacto, disminuye (aumenta) la distancia respecto al óptimo.

Como es bien sabido, si bien en el sector privado puede resultar relativamente sencillo diseñar una función objetivo satisfactoria, no es posible disponer de una función objetivo óptima para el análisis real de una "Huella Hídrica" compleja, que abarca muchos factores (sociales, ambientales, económicos, fiscales...). Al no poder construirse una función objetivo para los sectores públicos y privados con mejores propiedades que cualquier otra, existe un amplio abanico de posibilidades para la elección de una batería de criterios que ayuden a la toma de decisiones. Los sistemas más empleados en la práctica para la evaluación de proyectos, como el tan acreditado Análisis CosteBeneficio, se basan en el criterio de Kaldor: se examina si los beneficios totales exceden y cual es su incidencia en la sociedad. Dado que la noción de costes y de beneficios depende de la definición de la función objetivo que se pretende optimizar, con lo que se puede realizar una separación de costes y beneficios en directos e indirectos.

De igual modo, al tratarse de un estudio geográfico y económico es preciso analizar las diferentes escalas espacio-temporales y dimensiones de análisis ya que cada nivel de escala muestra diferentes problemas, cuestiones a resolver y teorías a formular (Dollfus, Mayr, 2006). Por ello, es preciso tomar escalas de magnitudes comparables, que permitan analizar los costes y los beneficios de forma concreta. La clasificación más extendida establece los ámbitos, atendiendo a la realidad española:

\begin{tabular}{|l|l|l|}
\hline- Internacional: & - Nacional y Regional: & - Local: \\
\hline$\bullet$ Mundial & $\bullet$ Nacional & $\bullet$ Comarcal \\
\hline$\cdot$ Continental (UE) & $\bullet$ Comunidades Autónomas & $\bullet$ Municipal (Agenda 21 local) \\
\hline & $\bullet$ Provincial & \\
\hline
\end{tabular}

Fuente: Elaboración propia 
Con todo ello, se ha establecido una misma función de utilidad (tipo CobbDouglas) para cada uno de los sectores económicos (primario, secundario y terciario) independientemente del peso total que tiene cada sector en la economía española. El análisis se ha realizado, tomando como referencia la variable tiempo (t) del año 2008 y en un espacio (i) que es el conjunto territorial de España. Y que se analizará en el apartado de metodología.

\subsubsection{CARACTERÍSTICAS BÁSICAS DEL ANÁLISIS COSTE-BENEFICIO.}

En nuestro estudio, hemos partido del análisis sectorial de la "Huella Hídrica" de España, atendiendo a sus funciones de demanda, en el año 2008, con el objetivo final de realizar un Análisis Coste-Beneficio en el que se pueda maximizar los beneficios sociales que se pueden derivar del uso del recurso hídrico o, más formalmente, maximizar el bienestar social.

Con todo ello, se hace imprescindible hacer referencia al concepto de excedente del consumidor, propio de la Economía del Bienestar (Welfare Economics), que intenta medir las ganancias de bienestar de los individuos; es decir, "el excedente del consumidor puede definirse como la diferencia entre el precio que el consumidor estaría dispuesto a pagar antes de quedarse sin un bien, y el precio que realmente paga"

Llegados a este punto, se nos plantea una problemática, y es poder generalizar los gustos y preferencias de toda la población para poder estudiar los excedentes totales de toda la población. Con lo que si suponemos que las funciones individuales de utilidad son idénticas, podríamos medir el aumento del bienestar social que se produce del consumo de "Huella Hídrica" en el total de la geografía española.

Sin embargo, como la constancia de la utilidad marginal de la renta y el enfoque cardinal de la utilidad supuestos que subyacerían a esta operación de agregación, plantean importantes dudas teóricas, nos vemos abocados a recurrir al criterio de Pareto y, más en particular, al principio de compensación que suaviza y amplía las posibilidades de aplicación de este criterio. Según este criterio los beneficios obtenidos de la producción, comercialización y consumo de "Huella Hídrica" podrían hacer frente a los costes de los mismos (contemplación de la compensación de costes). A pesar de todo, también aquí aparecerían problemas teóricos y metodológicos ya que, por un lado, no existiría compensación real, debido normalmente a los altos costes de transacción que comportaría su valoración. Y, por otro lado, la compensación variaría según la calculemos antes o después de realizar el proyecto, puesto que éste modificaría la estructura de precios relativos.

En suma, el ACB se fundamenta en estas ideas de referencia de la Economía del Bienestar, aunque su desarrollo operativo obedezca a un enfoque más pragmático debido a los obstáculos teóricos que se han mencionado. 


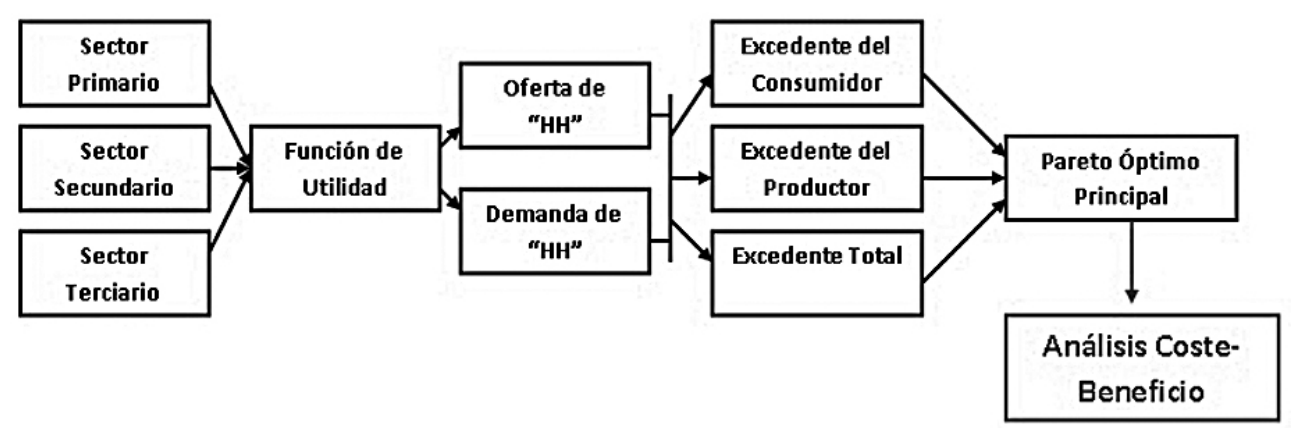

Fuente: Elaboración propia

Por otra parte, señalar que el excedente total es la suma de los excedentes de consumidores y productores o beneficios totales netos de la sociedad. La variación en el excedente total como consecuencia de este estudio mide el beneficio social neto producido por el estudio. En primer lugar debemos desglosar los distintos excedentes que configuran el excedente total $(E$. Total $=E$. Consumidor + E. Productor):

El excedente del consumidor es la valoración bruta de la cantidad consumida de "Huella Hídrica" de un bien o servicio menos el coste en el que ha tenido que incurrir para poder consumir esta misma cantidad (todo ello en términos monetarios). El excedente del productor es la diferencia entre el ingreso total percibido y el coste total de producir la cantidad vendida de "Huella Hídrica" de un bien o servicio. El excedente total es la suma del excedente del consumidor más el excedente del productor: la valoración bruta de la cantidad consumida de un bien menos el coste total necesario para producir dicha cantidad.

Por ello, en nuestro estudio, atendiendo a la metodología a uso, hemos analizado los excedentes sectoriales (agrícola, industrial y doméstico) de "Huella Hídrica" en España, por subsectores, en el año 2008. El principal problema que encontramos al estudiar los diferentes costes-beneficios y sus correspondientes excedentes (consumidor, productor y total), es la propia concepción del agua como producto en todos los componentes del ciclo del hidrológico. La perdida de recurso hídrico y la falta de datos respecto a la cantidad de agua "clandestina" o "no declarada" que se emplea en buena parte de la producción de bienes y servicios de "Huella Hídrica" dificulta la obtención de unos resultados completamente óptimos. De hecho, la valoración del consumidor por unidad consumida va aumentando, a medida que aumenta la cantidad consumida, con lo que presenta una valoración marginal creciente". Lejos de lo que pudiésemos pensar, la tendencia es creciente como consecuencia de esa situación económica expansiva de España, que incrementó sustancialmente el poder adquisitivo de 
la población (no siempre ligado a un aumento progresivo del nivel de renta, sino más bien del mejor acceso al crédito) lo que ha supuesto una mejora en la calidad de vida de los habitantes, un nivel de vida asociado al que "el que más tiene, más vale.

De igual modo, debemos tener en cuenta que, a la hora de hablar de demanda, hemos empleado el Agua Directa consumida por los consumidores de productos agrícolas, ganaderos, silvícolas, pesqueros, industriales, de la construcción, turísticos y domésticos, con lo que las valoraciones marginales difieren considerablemente, atendiendo a los distintos bienes y servicios. Al tratarse de una valoración económica de la demanda de "Huella Hídrica" no debemos olvidarnos que las elasticidadesprecio en cada uno de los Sectores es diferente con lo que, se hace imprescindible realizar un análisis sectorial distinto para el Sector primario o agrario, el Sector Industrial y de la Construcción, y el Sector Doméstico.

De igual modo, encontramos el problema de la diversidad de gustos, preferencias y necesidades de consumo de los distintos agentes económicos, con lo que se hace imprescindible homogeneizar, mediante parámetros $(\gamma \mathrm{i})$, dichas características individuales para facilitar el estudio. De este modo, se han estipulado diferentes parámetros (unidad consumida-valoración marginal) entre los distintos sectores económicos. De este modo, se han estipulado diferentes parámetros (unidad consumida-valoración marginal) entre los distintos sectores económicos.

\subsection{METOdologíA DE CÁlCULO DEL COSTE-BENEFICIO DE LA "HUELLA HIDRICA" EN ESPANA, POR SECTORES ECONOMICOS}

La metodología de cálculo del "coste-beneficio" de la "Huella Hídrica" de nuestro país, vamos a aplicarla a los sectores económicos.

\section{a) Sector Primario o Agrario:}

$$
U=U(x, y)=X_{i t}^{\alpha} \cdot Y_{i t}^{\beta}
$$

En los que $\mathrm{X}$ representa la superficie de tierra de cultivo y pastos, e $\mathrm{Y}$ el valor de la "Huella Hídrica" (Suma total del Agua Directa Total del Sector Primario, el Agua Total Interna, el Agua procedente del Comercio Exterior). Donde $\mathrm{x}$ depende a su vez de $\mathrm{Y} ; \mathrm{X}=\mathrm{f}(\mathrm{Y})$, ya que se pretende averiguar si " $\mathrm{Y}$ " es un coste o un beneficio en términos de la función objetivo $\mathrm{U}$.

$$
U=U(x, y)=\left(Y_{i t}^{\beta}\right)_{i t}^{\alpha} \cdot Y_{i t}^{\beta}
$$

Con lo que debemos hallar las derivadas parciales de la utilidad respecto de $\mathrm{X}$ como de Y:

Derivada Parcial respecto de $\mathrm{X}: \quad \frac{\delta U}{\delta X}=\alpha X_{i 2008}^{\alpha-1} \cdot Y_{i 2008}^{\beta}$

Deriva Parcial respecto de Y: $\quad \frac{\delta U}{\delta Y}=X_{i 2008}^{\alpha} \cdot \beta Y_{i 2008}^{\beta-1}$ 


$$
\frac{d U}{d X}=\frac{\delta U}{\delta X}+\left(\frac{\delta U}{\delta Y}\right) \cdot\left(\frac{\delta Y}{\delta X}\right)
$$

Donde:

$\frac{d U}{d X} \quad$, es el Efecto Total

\begin{tabular}{|c|c|}
\hline$\frac{\delta U}{\delta X}$ & Comportamiento de $\mathrm{X}$ \\
\hline$>0$ & Beneficio directo \\
\hline$<0$ & Coste directo \\
\hline$=0$ & negligible \\
\hline
\end{tabular}

$\frac{\delta U}{\delta X} \quad$, es la derivada Parcial respecto de X: Efecto Directo.

$\left(\frac{\delta U}{\delta Y}\right) \cdot\left(\frac{\delta Y}{\delta X}\right) \quad$, es el Efecto Indirecto o cruzado

Los datos utilizados en el estudio de la "Huella Hídrica" tienen su origen en el desglose del sector primario en agricultura, ganadería, pesca y selvicultura.

Cuadro 3. Análisis de los costes y los beneficios de la "Huella Hídrica" en el Sector Primario

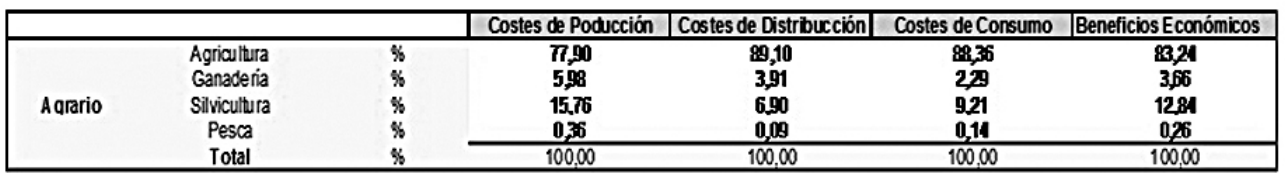

Fuente: Elaboración propia, a partir de datos del Ministerio de Medio Ambiente, Rural y Marino (2009)

b) Sector Secundario (Industria y Construcción):

$$
U=U(x, y)=X_{i t}^{\alpha} \cdot Y_{i t}^{\beta}
$$

En los que X representa el VAB de la producción industrial, e Y el valor de la "Huella Hídrica" (Suma total del Agua Directa Total del Sector Secundario, el Agua Total Interna, el Agua procedente del Comercio Exterior). Donde x depende a su vez de $\mathrm{Y} ; \mathrm{X}=\mathrm{f}(\mathrm{Y})$, ya que se pretende averiguar si " $\mathrm{Y}$ " es un coste o un beneficio en términos de la función objetivo $\mathrm{U}$.

$$
U=U(x, y)=\left(Y_{i t}^{\beta}\right)_{i t}^{\alpha} \cdot Y_{i t}^{\beta}
$$

Con lo que debemos hallar las derivadas parciales de la utilidad respecto de $\mathrm{X}$ como de Y:

Derivada Parcial respecto de X: $\quad \frac{\delta U}{\delta X}=\alpha X_{i 2008}^{\alpha-1} \cdot Y_{i 2008}^{\beta}$

Deriva Parcial respecto de Y: $\quad \frac{\delta U}{\delta Y}=X_{i 2008}^{\alpha} \cdot \beta Y_{i 2008}^{\beta-1}$ 
$\frac{d U}{d X}=\frac{\delta U}{\delta X}+\left(\frac{\delta U}{\delta Y}\right) \cdot\left(\frac{\delta Y}{\delta X}\right)$

Donde:

$\frac{d U}{d X} \quad$, es el Efecto Total

\begin{tabular}{|c|c|}
\hline$\frac{\delta U}{\delta X}$ & Comportamiento de $\mathrm{X}$ \\
\hline$>0$ & Beneficio directo \\
\hline$<0$ & Coste directo \\
\hline$=0$ & negligible \\
\hline
\end{tabular}

$\frac{\delta U}{\delta X} \quad$, es la derivada Parcial respecto de $\mathrm{X}$ : Efecto Directo.

$\left(\frac{\delta U}{\delta Y}\right) \cdot\left(\frac{\delta Y}{\delta X}\right) \quad$ es el Efecto Indirecto o cruzado

Los datos utilizados en el estudio de la "Huella Hídrica" tienen su origen en el desglose del sector secundario en industria (todas las industrias analizadas en la oferta y demanda de Huella Hídrica) y el sector de la construcción.

Cuadro 4.- Análisis de los costes y los beneficios de la "Huella Hídrica" en el Sector Industrial y de la Construcción

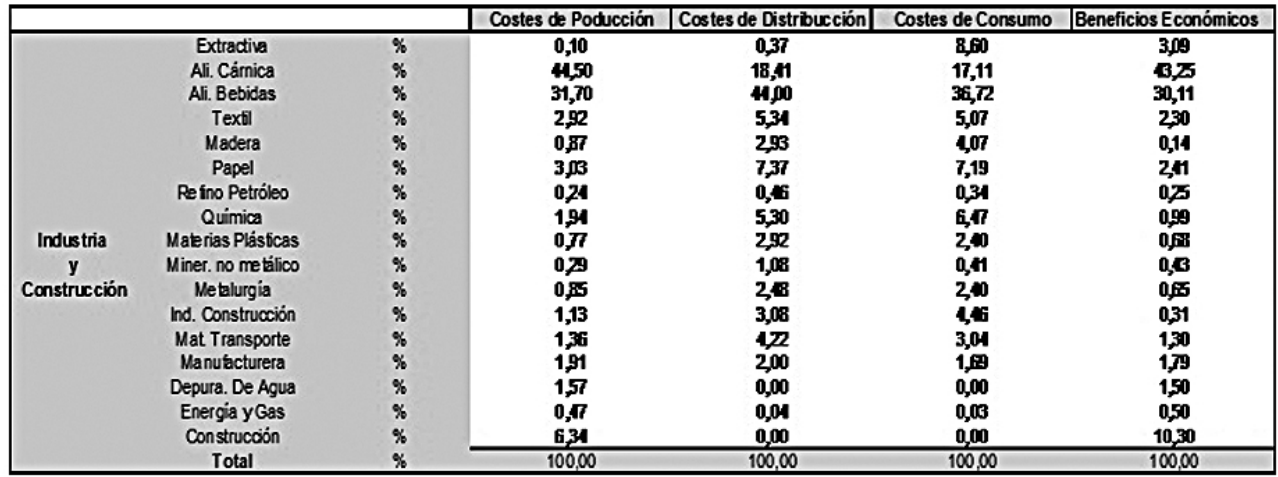

Fuente: Elaboración propia, a partir de datos del Ministerio de Medio Ambiente, Rural y Marino (2009)

\section{c) Sector Terciario (Servicios, Usos Domésticos, Turismo y Hostelería):}

$$
U=U(x, y)=X_{i t}^{\alpha} \cdot Y_{i t}^{\beta}
$$

En los que $\mathrm{X}$ representa el uso doméstico, de los servicios hosteleros y turísticos, e Y el valor de la "Huella Hídrica" (Suma total del Agua Directa Total del Sector Terciario, el Agua Total Interna, el Agua procedente del Comercio Exterior). Donde $\mathrm{x}$ depende a su vez de $\mathrm{Y} ; \mathrm{X}=\mathrm{f}(\mathrm{Y})$, ya que se pretende averiguar si " $\mathrm{Y}$ " es un coste $\mathrm{o}$ un beneficio en términos de la función objetivo $U$. 


$$
U=U(x, y)=\left(Y_{i t}^{\beta}\right)_{i t}^{\alpha} \cdot Y_{i t}^{\beta}
$$

Con lo que debemos hallar las derivadas parciales de la utilidad respecto de $\mathrm{X}$ como de Y

Derivada Parcial respecto de X: $\quad \frac{\delta U}{\delta X}=\alpha X_{i 2008}^{\alpha-1} \cdot Y_{i 2008}^{\beta}$

Deriva Parcial respecto de
$\frac{d U}{d X}=\frac{\delta U}{\delta X}+\left(\frac{\delta U}{\delta Y}\right) \cdot\left(\frac{\delta Y}{\delta X}\right)$

Donde:

$\frac{d U}{d X} \quad$, es el Efecto Total

$$
\frac{\delta U}{\delta Y}=X_{i 2008}^{\alpha} \cdot \beta Y_{i 2008}^{\beta-1}
$$

$\delta U$

$\frac{\partial U}{\delta X}$, es la derivada Parcial respecto de X: Efecto Directo.

$\left(\frac{\delta U}{\delta \mathrm{Y}}\right) \cdot\left(\frac{\delta \mathrm{Y}}{\delta \mathrm{Y}}\right) \quad$, es el Efecto Indirecto o cruzado

\begin{tabular}{|c|c|}
\hline$\frac{\delta U}{\delta X}$ & Comportamiento de $\mathrm{X}$ \\
\hline$>0$ & Beneficio directo \\
\hline$<0$ & Coste directo \\
\hline$=0$ & negligible \\
\hline
\end{tabular}

Los datos utilizados en el estudio de la "Huella Hídrica" tienen su origen en el desglose del sector terciario en los usos domésticos y los servicios (hosteleros, turísticos...).

\begin{tabular}{|c|c|c|c|c|c|c|}
\hline & & & Costes de Poducción & Costes de Distrbucción & Costes de Consumo & Beneficios Económicos \\
\hline Uso & Residual & $\%$ & 0,98 & 0,00 & 0,00 & 0,0 \\
\hline Doméstico & Turismo & $\%$ & 281 & 0,00 & 5,72 & 9,53 \\
\hline y & Hosteleria & $\%$ & 2,09 & 0,00 & 0.24 & $\$ 0,16$ \\
\hline \multirow[t]{2}{*}{ Turismo } & Servicios y Doméstico & $\%$ & 53,23 & - & 새어 & 40,32 \\
\hline & Total & $\%$ & 100,00 & 0,00 & 100,00 & 100,00 \\
\hline
\end{tabular}

Cuadro 5. Análisis de los costes y los beneficios de la "Huella Hídrica" en el Sector Terciario

Fuente: Elaboración propia, a partir de datos del Ministerio de Medio Ambiente, Rural y Marino (2009)

\subsection{ANÁLISIS COSTE-EFICIENCIA.}

Junto con lo tratado respecto del "coste-beneficio" de la "Huella Hídrica", cobra relativo interés el denominado "coste-eficiencia", ya que si bien, el análisis costebeneficio nos permite realizar una valoración monetaria de la realidad económica de la "Huella Hídrica" en España, no nos permite tener en cuenta cuestiones tan relevantes como los costes de oportunidad o los costes sociales o ambientales, que se pueden generar por la explotación y comercialización del recurso hídrico. Por ello, es necesario realizar un estudio de los costes-eficiencia que se derivan de la realidad compleja de la "Huella Hídrica" en un país como España, en el que, como ya hemos 
visto, se da una oferta tendencialmente creciente con la demanda de "Huella Hídrica", pero estrechamente dependiente de la renta, las condiciones socio-demográficas, y, los flujos de comercio de bienes y servicios.

La estructura del análisis coste-eficiencia, grosso modo, la encontramos recogida en el cuadro siguiente.

Cuadro 6.- Estructura del Análisis Coste-Eficiencia

\section{ESTRUCTURA DEL ANÁLISIS COSTE-EFICACLA}

SUBSIST. INFORMACIÓN 2015

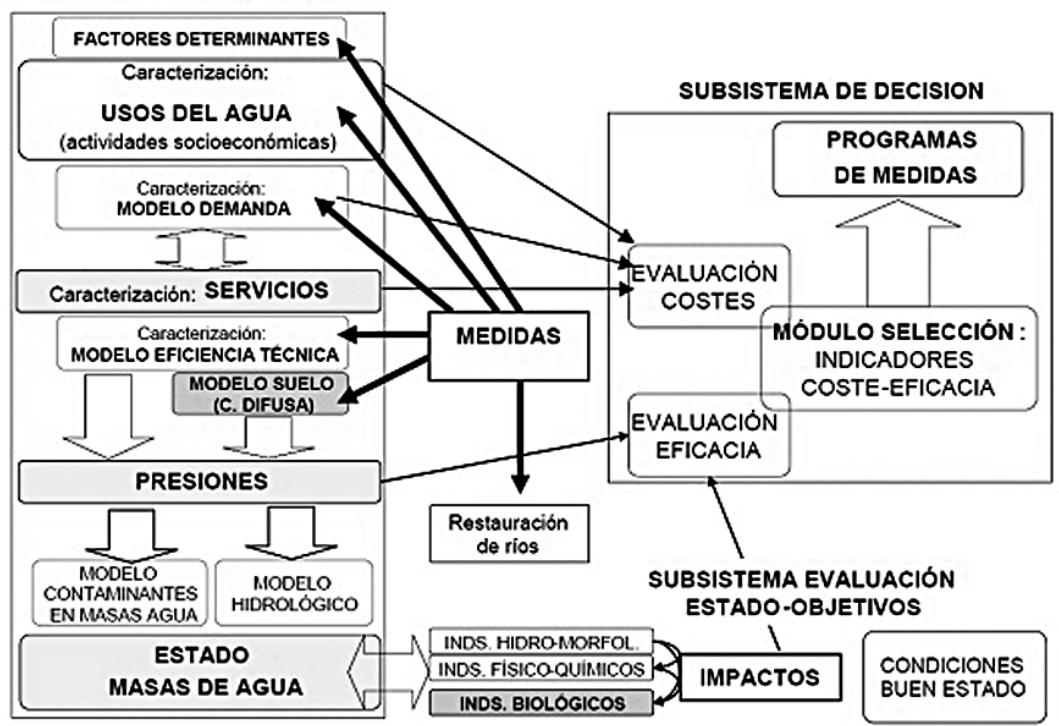

Fuente: Josefina Maestu (2006)

La noción de eficiencia (Albi et alias, 2009) se refiere al mejor uso posible de los recursos limitados de los agentes económicos. Un sistema económico es eficiente si no desperdicia recursos, haciendo máximo el bienestar de los individuos. Esto es, llamamos eficiente a un sistema económico en el que no es posible reasignar los recursos existentes de tal forma que algún (o algunos) individuo (s) mejore (n) sin que otro ( $u$ otros) empeore (n). A una asignación eficiente se la denomina Pareto eficiente o Pareto óptima.

El análisis coste-eficiencia supone una simplificación del de coste-beneficio, ya que éste nos ha permitido evaluar monetariamente los objetivos perseguidos, pero una buena parte de la información queda indeterminada por el problema de la imposibilidad de hacer un estudio monetario de los costes vs. beneficios sociales o ecológicos, en nuestro caso de la Huella Hídrica en algunos sectores o en ciertas Comunidades Autónomas. El análisis coste-eficiencia se realiza de manera análoga al análisis coste-beneficio, pero tomando como base la eficiencia, entendida ésta como la mejora en el bienestar (aunque la literatura económica considera que la efi- 
ciencia está únicamente vinculada con la utilidad en vez de con el bienestar) de los individuos de una determinada área geográfica (permite, pues, analizar los costes de oportunidad del consumo vs. producción de un bien escaso como es el "agua").

Para realizar dicho análisis debemos tener en cuenta que, el estudio de la eficiencia, se puede realizar en términos del output o resultado (por ejemplo, el volumen total de agua consumida por una persona en su casa, o el Kg. de tomates que se producen en una huerta), o en términos del input o recurso empleado en el producción (por ejemplo, los litros de agua empleados en la producción de una camiseta o el volumen total de agua que bebe una vaca).

Cuadro 7.- Matriz Input-Output

\begin{tabular}{|c|c|c|l|}
\hline DATO INICIA & Objetivo & Medida de Eficiencia & Valores de Referencia \\
\hline Dado un Output & Minimizar el Input & Input Mínimo/Input Real & $\begin{array}{l}=1 \rightarrow \text { Óptimo } \\
<1 \rightarrow \text { Ineficiente }\end{array}$ \\
\hline Dado un Input & Maximizar el Output & Output Real/Output Máximo & $\begin{array}{l}=1 \rightarrow \text { Óptimo } \\
<1 \rightarrow \text { Ineficiente }\end{array}$ \\
\hline
\end{tabular}

Fuente: Elaboración propia, a partir de Valiño, A. (2004)

Hay que observar que la evaluación de la eficiencia se está aquí planteando como la comparación entre una situación real y una hipotética que suponemos óptima. Por eso, es importante la selección de algún indicador que nos aproxime a lo que técnicamente es óptimo, para así estudiar la eficiencia de una unidad productiva o poder comparar unidades entre sí. En este sentido, las técnicas de evaluación de la eficiencia que utilizan este enfoque comparativo son de dos tipos. Las que adoptan como término de referencia óptimo el comportamiento promedio de todas las unidades. Una variante dentro de este tipo es la técnica que se basa en el comportamiento medio esperado de todas las unidades teniendo en cuenta las diferencias en las circunstancias socioeconómicas en las que se desenvuelven las mismas. El otro tipo de técnicas son las que relacionan la eficiencia de una unidad con el mejor comportamiento mostrado por alguna de las unidades, el llamado análisis "frontera". Las unidades eficientes se sitúan en la frontera de producción o de coste, las ineficientes se encuentran por debajo de la frontera de producción o por encima de la frontera de coste (Valiño et alii, 2004).

\subsection{RESULTADOS DEL ANÁLISIS COSTE-BENEFICIO Y ANÁLISIS COSTE- EFICIENCIA DE LA "HUELLA HÍDRICA" EN ESPAÑA:}

Antes de ver los diferentes costes y beneficios que se generan de la compleja realidad de la "Huella Hídrica", se hace imprescindible analizar detalladamente los distintos costes que repercuten, directa o indirectamente, sobre los beneficios económicos, ecológicos y sociales, que de dicha "Huella" se derivan.

\subsubsection{ANÁLISIS DE LOS COSTES DE LA “HUELLA HÍDRICA” EN ESPAÑA.}

$\mathrm{Al}$ tratar de nuestro país, podemos destacar los costes siguientes: 


\begin{tabular}{|c|}
\hline COSTES \\
\hline Costes de Oportunidad \\
\hline Costes de Capital \\
\hline Costes de Obtención \\
\hline Costes de reposición \\
\hline Costes de Generación \\
\hline Costes de Reasignación \\
\hline Costes Económicos \\
\hline Costes Ambientales \\
\hline Coste Sociales \\
\hline
\end{tabular}

Fuente: Elaboración propia, a partir de EEB (2001)

El análisis y la aplicación de los distintos modelos Coste-Beneficio y CosteEficiencia de nuestra "Huella Hídrica", nos lleva a diferenciar los costes monetarios y no monetarios, de la producción y del consumo de "Huella Hídrica", recogidos en el cuadro adjunto.

Cuadro 8.- Cuadro conceptual de los Costes de la "Huella Hídrica"

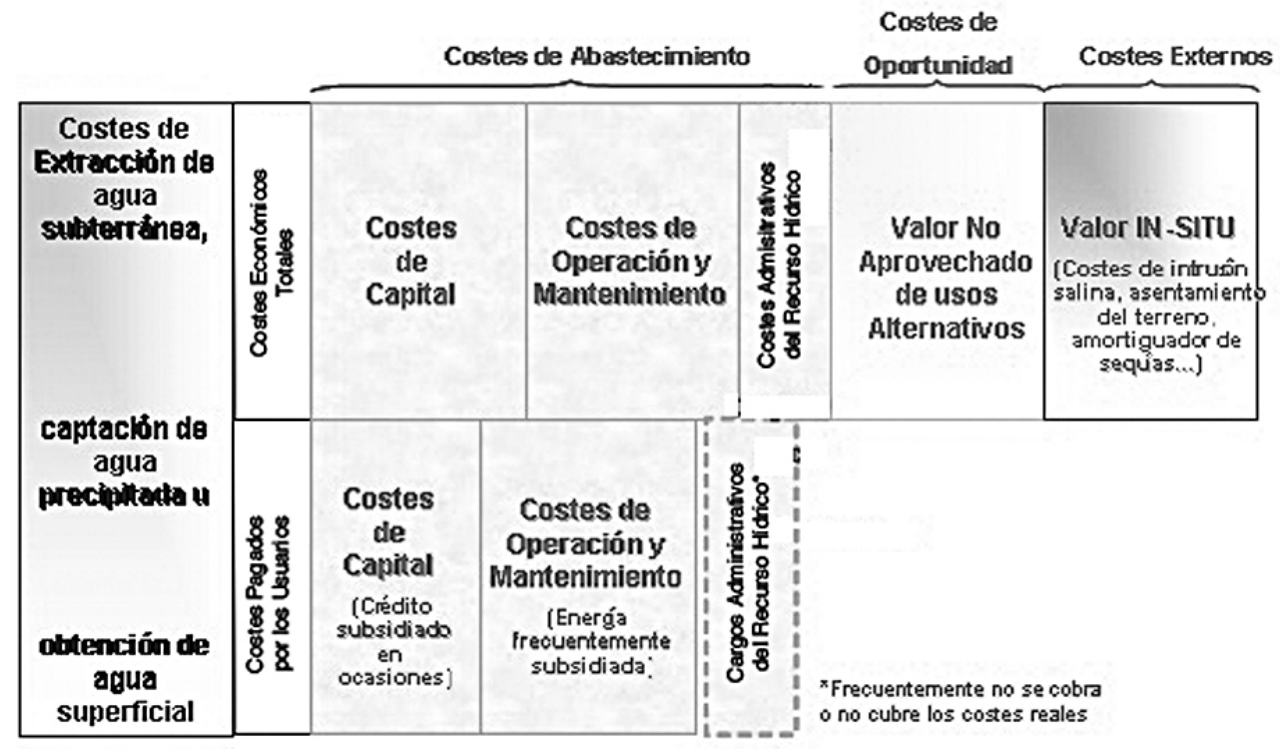

Fuente: Elaboración propia, a partir del Grupo Base del GW•MATE (2006)

Detengámonos en su descripción.

\section{a) Los Costes de oportunidad o Costes del Recurso.}

Al hablar de Costes de Oportunidad en la "Huella Hídrica" nos estamos refiriendo a los costes de disponibilidad que resultan de la escasez de agua. Es decir, todos aquellos costes sociales, económicos y ecológicos, que se derivan de la falta de acce- 
so al recurso hídrico para la producción de bienes y servicios y, para el abastecimiento rural y urbano de una sociedad (por cuestiones de escasez). La falta de acceso al agua, incide en la "Huella Hídrica" de un país, limitando la producción y limitando la productividad pero, en muchos casos, las malas praxis en los usos del recurso hídrico es lo que genera dichos costes de oportunidad. Dentro de los costes de oportunidad en la "Huella Hídrica" son;

\section{a.1. Costes vinculados o relacionados con la escasez:}

Tal y cómo hemos visto anteriormente, el recurso hídrico empleado en la producción y consumo de bienes y servicios, es un bien escaso, estrechamente relacionado a las condiciones climáticas y a las malas prácticas de uso. Con ello, se generan costes de oportunidad en la obtención y consumo de "Huella Hídrica". Dicha escasez puede darse en un momento concreto, durante el verano (vinculado a la falta de lluvias, disminución de las nevadas, el aumento de las temperaturas...) o puede prolongarse a lo largo del tiempo (en zonas más desérticas). El territorio español padece, con regularidad e intensidad diversa según regiones, los efectos de las sequías. La reducción de recursos pluviométricos provoca, a su vez, un descenso de la oferta de agua disponible para satisfacer unas demandas (agrícolas, urbano-turísticas, industriales e hidroeléctricas) en permanente expansión desde mediados del siglo XX. De esta forma, un hecho natural puede verse agravado por la intervención humana, al aumentar la vulnerabilidad de los sistemas de suministro de agua.

a.2. Costes de oportunidad generados por riesgos naturales (no sólo la, ya mencionada, sequía, sino que también las fuertes riadas, el granizo que destruye las cosechas, los incendios forestales que merman los bosques...)

España es uno de los espacios geográficos de Europa más afectado por los peligros de la naturaleza, merced a su propia posición geográfica, su carácter de península rodeada de mares, su topografía y la ocupación humana, de época histórica, que se ha dado en su territorio. Los perjuicios económicos ocasionados por acontecimientos atmosféricos extraordinarios representan, según años, entre $0,15 \%$ y $1 \%$ del Producto Interior Bruto (PIB.), correspondiendo un elevado porcentaje de éstos (60$75 \%$ ) al sector agrario. En el período 1990-2008 las pérdidas anuales por riesgos de la naturaleza en España se ha elevado a 12.560 millones de $€$.

\section{a.3. Costes de oportunidad por las condiciones económicas individuales de la población:}

Otro factor, amén de la escasez del recurso hídrico, lo encontramos en las diferencias socioeconómicas de la población, que incide tanto positiva como negativamente en la compra de bienes y servicios, en la producción agrícola e industrial, en el abastecimiento de agua doméstica, en definitiva en el consumo de "Huella Hídrica". En España, el desarrollo económico expansivo de los últimos años, junto con las posibilidades financieras de acceso al crédito de las familias y empresas, han favorecido el aumento de la demanda de "Huella Hídrica" en nuestro país. De igual modo, las Políticas Comunitarias generaron ingresos (como los Fondos Europeos FEDER, FEOGA...) e incrementaron el poder adquisitivo de los productores en el sector agrario, con lo que se redujeron los costes de oportunidad en dicho sector (a 
pesar de ello, han generado otros costes asociados como, por ejemplo, costes ambientales y de degradación). Como ya vimos anteriormente, el crecimiento entre los distintos sectores económicos fue desigual pero, a fin y a postre, creciente.

\section{a.4. Costes de oportunidad por la financiación empresarial:}

A pesar de que en los últimos años, se ha producido una mejora en las infraestructuras, tanto de extracción, captación, depuración, desalación y distribución del recurso hídrico en nuestro país, las dificultades de acceso, en muchas regiones españolas, ha incidido negativamente en la producción (sobre todo agraria e industrial) en España, generando numerosos conflictos políticos. Costes de oportunidad en el acceso al agua de determinados territorios que generan conflictos, como por ejemplo en los transvases de aguas entre Cuencas. La mayor parte de los expertos en estos temas suele admitir hoy que los conflictos hídricos no se deben normalmente a la escasez física de agua sino a la mala, a veces pésima, gestión que realizan los poderes públicos de este recurso (Llamas, 2005).

\section{a.5. Costes de oportunidad vinculados a la accesibilidad al mercado:}

No toda la "Huella Hídrica" producida y demanda por una sociedad, tiene la posibilidad de salir al mercado, nacional e internacional. Tal y como hemos podido ver en el punto anterior, España es un país consumidor de "Huella Hídrica" pero también es un país, fundamentalmente importador de productos, bienes y servicios. Las Leyes de oferta y demanda, que se rigen en el propio país o en la Unión Europea, en muchas ocasiones difieren de las del resto de países, con los que los flujos de comercio de Agua Virtual en particular y de "Huella Hídrica" en general se ven limitados.

La globalización y la mundialización han producido que, algunos países sean dependientes totalmente de la importación de bienes y servicios, lo que les hace enormemente vulnerables a las decisiones gubernamentales, económicas o políticas, a la hora de acceder a un mercado que les abastezca de alimentos, ropa, agua potable,...

\section{b. Costes de reposición, obtención, generación y reasignación:}

La aplicación del recurso hídrico en un determinado uso, también conlleva el desabastecimiento de otros usos o funciones (incluidas las relacionadas con los organismos, ecosistemas y paisajes asociados) Las distintas de disponer de agua de determinada calidad surgen de las distintas fuentes de oferta o de las alternativas que ofrece la gestión de la demanda, derivadas del ahorro o la mejora de la eficiencia en el uso o de las ofertas de "Huella Hídrica" por parte de concesionarios que les sobra o sacan poco partido de ella: todo lo cual genera múltiples posibilidades y costes como costes de reposición, reasignación o costes de obtención (Naredo, J.M., 2010).

\section{b.1. Coste de reposición}

Dentro de los distintos costes a los que nos enfrentamos al hablar de la "Huella Hídrica" son los distintos costes de reposición del recurso hídrico, atendiendo a la fase de producción o de consumo en la que nos encontremos. Como bien hemos definido, el agua es un bien escaso, pero fundamental no sólo para la vida sino que también para el desarrollo de todas las actividades económicas de un país como España. Las pérdidas de recursos hídricos en los inputs (como hemos denominado anterior- 
mente a los bienes insumos) utilizados en la producción de outputs (bienes finales, agrarios, industriales o del sector servicios) son muy grandes, con lo que se hace imprescindible incurrir en ciertos cortes de reposición,

Dentro de los costes de reposición encontramos costes de reposición integral y costes de reposición parcial.

\section{b.1.1. Costes de reposición integral.}

El coste de reposición integral de la "Huella Hídrica" es el coste de reposición artificial del ciclo hidrológico completo en un punto determinado en la producción de bienes y servicios a partir del recurso hídrico. Con ello se generan costes de fabricación (tanto monetarios como energéticos) para poder incidir en la cantidad y calidad ofertada, con la mejor tecnología posible. Un ejemplo de ello son los costes en los que se incurren en la desalación o en la depuración del agua.

\section{b.1.2. Costes de reposición parcial.}

Por otro lado, los costes de reposición parcial en una masa de agua se basa en la aquellas actividades que se realizan con el fin último de conservar (no de regenerar como en el integral) y mejorar las producciones, aumentando la cantidad pero, también la calidad de los productos (en los que interviene el recurso hídrico). Estos costes son financiados en España, mayoritariamente, por subvenciones estatales y europeas.

\section{b.2. Coste de obtención del recurso.}

Los costes de obtención del recurso hídrico (insumo fundamental de la "Huella Hídrica") es aquel en el que se incurra para generar y reasignar el recurso hídrico necesario para la producción de bienes y servicios. Dentro de los costes de obtención (que, también pueden denominarse de extracción o captación) encontramos los costes de generación del recurso y de reasignación del recurso.

Los costes de obtención (extracción y captación) recogen todos los costes directos e indirectos relacionados con la gestión, operación y mantenimiento del servicio. Estos se pueden dividir en dos grupos: Costes Fijos y Costes Variables.

- Los Costes Fijos son los independientes de los niveles de consumo, e incluyen partidas tales como: Gastos de personal, donde figuran los costes de la plantilla adscrita al servicio de suministro de agua a poblaciones.

- Gastos de conservación y mantenimiento, que agrupan conceptos como adquisición de materiales, trabajos realizados por terceros, alquileres, gastos generales y administrativos, etc.

- Los Costes Variables, dependientes de los niveles de consumo, que reúnen conceptos como: Consumos (energía, reactivos en el tratamiento y análisis de agua, adquisición de caudales en "alta", etc.).

- Costes de gestión, que incorporan al coste los servicios de lectura, facturación, cobro e impagados, entre otros.

Los costes de generación del recurso en un determinado territorio es el coste (monetario y energético) de poner en ese territorio una determinada cantidad de agua, con la mejor tecnología posible e intentando hacer un uso eficiente de las dotaciones renovables de agua accesible en dicho territorio. Este coste correspondería a 
la opción más barata de abastecer agua captándola, impulsándola, tratándola y transportándola hasta ponerla en ese punto del territorio con la cantidad y calidad que se precisen. Este coste ya no puede ser ajeno a la escasez física de las fuentes disponibles en el territorio: por eso para determinarlo hay que precisar la cantidad y calidad de agua deseada, habida cuenta la limitación de esas fuentes (en cantidad y calidad) y plantea, además, costes de oportunidad respecto al posible uso alternativo de esas fuentes, por el que compiten otros puntos del territorio. Por ejemplo, el uso agrario del agua en la fuente, al evaporar una buena parte de ella y concentrar las sales en el resto, limita la posibilidad de utilizarla aguas abajo. Este coste sintetizaría así los correspondientes a la combinación de fuentes y medios disponibles, tomando los de menor coste para conseguir la cantidad y calidad de agua propuesta en el punto del territorio que se determine. Cabe construir, así, el mapa del coste (energético y monetario) de generación de los recursos utilizados y otro de la generación de nuevos recursos para planear los usos en un territorio, atendiendo a lo que en economía se llaman costes marginales. Esto es lo que más o menos ha venido haciendo implícitamente la especie humana a lo largo de su historia, al emplazar las aglomeraciones de población en lugares con buenas dotaciones de agua y, en general, adaptando los usos al agua disponible. Sin embargo esto es lo que no ocurre en los últimos tiempos cuando, al amparo de las nuevas posibilidades de fabricación, transporte y abastecimiento de agua, se promueven, por ejemplo, grandes aglomeraciones de población y actividades muy exigentes en agua en zonas extremadamente áridas, sin reparar en los costes que conlleva su abastecimiento. Y esto es lo que trata de controlar la Directiva Marco del Agua, cuando habla de tener en cuenta el coste del recurso y el coste ambiental que ocasiona su uso, a fin de poner de nuevo la cordura económica en la gestión del agua y el territorio contando con el nuevo marco tecnológico.

De igual modo, se puede incurrir en costes de reasignación del recurso mediante el reciclaje y la depuración de las aguas ya utilizadas, para hacer frente al problema de la escasez, pero también para favorecer el ahorro energético. Estos costes tienen dos componentes de costes agregados (energético, monetario y de inversión) uno orientado hacia el ahorro y la mejor de la eficiencia (operaciones de captación, impulsión, transporte o tratamiento).

En el componente monetario cobran gran importancia los costes de oportunidad y la disposición a pagar y a cobrar por el agua de los distintos usuarios y concesionarios que pueden dar lugar a transacciones mercantiles generalizadas articuladas en forma de "bancos" o de "mercados de agua", atendiendo a las orientaciones del marco institucional y normativo. Los precios del agua que afloren en estas transacciones dependerán de ese marco institucional. En la medida en la que éste favorezca la plena repercusión sobre los precios de los costes de las operaciones de ahorro y abastecimiento incluidas en el primer componente antes mencionado, así como la amplitud y transparencia de dichas transacciones, los precios informarán solventemente del coste de reasignación del recurso. Si existe esta transparencia cabe suponer también que los usos más valorados quedarán satisfechos y que los costes de oportunidad no llegarán a superar la disposición a pagar de estos usos, salvo excepciones en las que, por razones sociales,... o ecológicas, se quieran asegurar ciertos 
abastecimientos a bajo precio. (Naredo, J.M., 2010). Así mismo, cabe suponer que no se pondrán en marcha operaciones de generación de nuevos recursos cuyo coste sea superior al coste de reasignación de los recursos ya existentes. Es decir, que una gestión económicamente razonable sugiere que el coste de generación de nuevos recursos no debería superar al coste de reasignación del recurso (como sintetiza el esquema adjunto). Como tampoco que el coste de generación de nuevos recursos llegue a superar al coste de reposición (integral o parcial) del recurso localmente disponible. La tradicional política de promoción de obras hidráulicas ha violado ambos principios de buena gestión en numerosas ocasiones.

Cuadro 9.- Reposición-Obtención y Reasignación-Generación de la "Huella Hídrica"

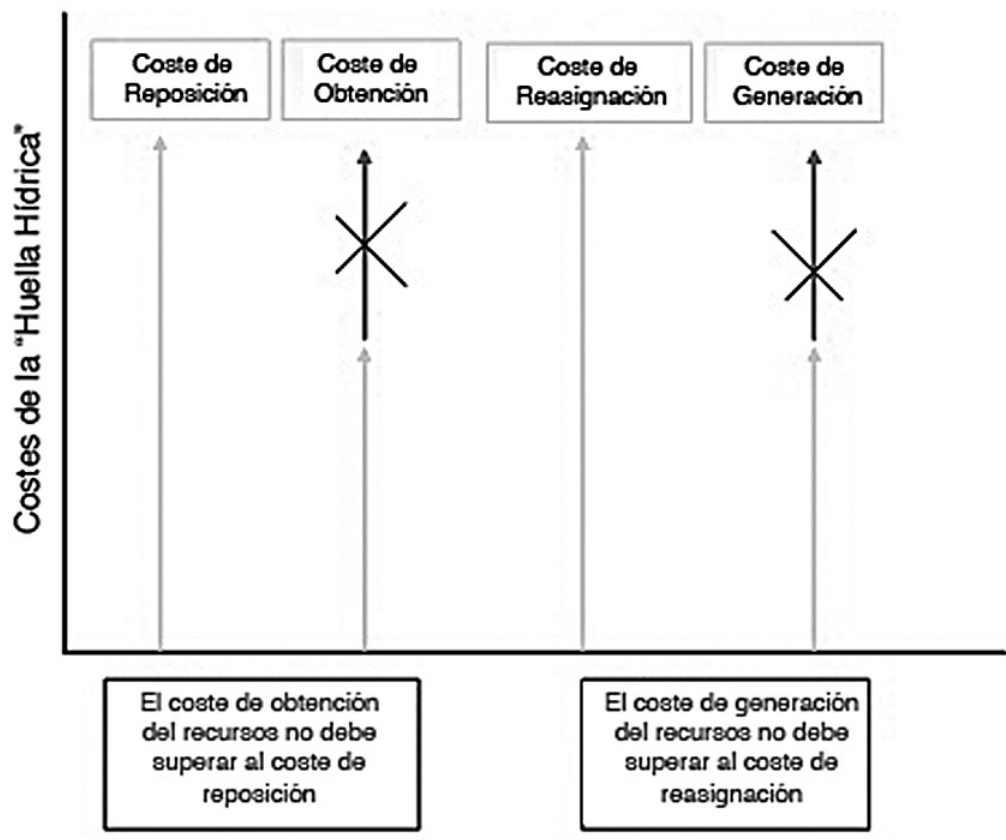

Fuente: Elaboración propia, a partir de Naredo, J.M. (2007)

El hecho de que no existan en España precios del agua fruto de transacciones institucionalizadas de forma amplia y transparente en forma de "bancos" o "mercados de agua" acarrea la desinformación sobre el coste local de reasignación del recurso y hace que se promuevan y subvencionen impunemente desde la administración megaproyectos hidráulicos con costes de generación de nuevos recursos previsiblemente muy superiores a los de reasignación local del recurso. (Naredo, J.M., 2010).

\section{c. Costes ambientales}

Los impactos locales pueden ocurrir por la sobreexplotación o la contaminación de las aguas superficiales y subterráneas, o debido a una reasignación del flujo de agua verde evaporada desde la vegetación natural a los cultivos. Los impactos ambientales en una cuenta hidrográfica pueden ocurrir cuando existen pequeñas 
extracciones de agua o flujos de residuos que se acumulan y causan impactos posteriores río abajo en ecosistemas acuáticos o terrestres adyacentes al río. A nivel global, todas las huellas hídricas que se van sumando crean una situación en la cual la escasez de agua dulce conduce a su sobreexplotación. Siendo importante analizar si esta situación se puede reducir o evitar. Cuando las captaciones son bastante pequeñas (menos de $100 \mathrm{~km} 2$ ), se realiza una evaluación ambiental a nivel micro. En este caso, se incluyen los impactos que se producen dentro de la zona donde se evalúa la "Huella Hídrica", pero los impactos aguas abajo no se incluirían en el estudio.

Se pueden identificar los puntos conflictivos o calientes de la "Huella Hídrica" de un producto, de un consumidor o de un productor en función de los componentes que se localizan en la cuenca donde se consume o se contamina agua a costa de la calidad de los ecosistemas naturales. En este nivel, el impacto de la "Huella Hídrica" de un producto, un consumidor o un productor, siempre dependerá de la suma de las huellas hídricas de todas las actividades en relación con los recursos disponibles de agua y su capacidad de asimilación (Sotelo et alii, 2010). A partir de la evaluación ambiental, surgen tres impactos importantes: la escasez de agua verde, la escasez de agua azul y el nivel de contaminación del agua.

\section{d. El coste de los servicios asociados al agua}

El coste de los servicios asociados a la "Huella Hídrica" es el coste monetario en el que se incurren en la captación, extracción, regulación, transporte del agua verde procedente de las precipitaciones o del agua azul de los ríos, lagos o embalses; el tratamiento de abastecimiento, recogida y depuración del agua gris. Todos estos costes son soportados por las Administraciones Públicas, tanto estatales como locales, encargadas de la regulación y control de dichas actividades. En España, gracias a la mejora en la obras hidráulicas (más eficientes, menos contaminantes y más baratas), los costes en los que se incurren tienden a ser menores, puesto que no generan nuevos costes asociados. Lo que si se generan son costes en investigación, en $\mathrm{I}+\mathrm{D}+\mathrm{i}$ para la creación de nuevas infraestructuras cada vez mejores, de mayor calidad, que maximicen los beneficios, minimizando los costes.

\section{e. Costes de comercialización vinculados a la Globalización.}

La Globalización, término acuñado a la situación actual de la economía moderna, ha favorecido la aparición de un modelo de producción flexible (vinculada a grandes cambios tecnológicos) que, junto a la apertura de los mercados, ha generado movimientos de capital y un comercio internacional de bienes y servicios a escala mundial. Esto, en muchos casos, ha supuesto un gran coste puesto que los efectos indirectos del consumo de un país se externalizan a otros.

En la agricultura, el agua sigue teniendo precios muy por debajo de su coste real, mientras que cada vez se usa más agua para procesar productos destinados a la exportación. Los costes asociados al uso del agua en el país exportador no se incluyen en el precio de los productos consumidos en el país importador. Los consumidores no suelen ser conscientes de los problemas en materia de agua de los países donde se producen los bienes que se consumen, ni pagan por ello. 
Otro coste asociado a las transferencias de agua virtual internacionales es que muchos países dependen cada vez más de la importación de bienes intensivos en agua de otros países. La creciente falta de autosuficiencia ha aumentado la vulnerabilidad de algunos países puesto que, en caso de que no se puedan importar bienes agrarios, puede suponer la muerte por inanición de un país.

\section{f. Costes Sociales.}

Desde una perspectiva social, la sostenibilidad de la "Huella Hídrica" se relaciona con temas como el reparto equitativo, los efectos externos, los oportunistas, el empleo y la salud humana.

El reparto equitativo se analiza por ejemplo, cuando en la zona hay un gran consumidor de agua que obtiene grandes beneficios por la producción de productos de exportación, mientras las Comunidades de alrededor no obtienen beneficio alguno y además sufren la contaminación ocasionada por este usuario. A nivel de cuenca hidrográfica, el reparto equitativo se analiza cuando la extracción de agua se realiza río arriba, se consumen grandes cantidades y la contaminación se produce a costa de los usuarios río abajo. En una escala global, la equidad toma mayor relevancia, porque algunos consumidores tienen una "Huella Hídrica" cinco veces superior que otros, y los recursos de agua dulce a nivel mundial son limitados. Aparte de la cuestión de la equidad dentro de esta generación, está la cuestión de la equidad intergeneracional.

Los efectos externos son muy frecuentes en el empleo de los recursos hídricos: los costes del consumo y de la contaminación por la población ubicada aguas arriba de una cuenca hidrográfica no compensan a los consumidores aguas abajo. Los oportunistas son aquellos que extraen agua de los acuíferos o de los ríos en mayor cantidad que otros (Sotelo et al ii, 2010).

En relación con el empleo, ocurre en muchas regiones que la producción de cultivos en una cuenca lleva a la sobreexplotación de los recursos hídricos disponibles, que se pone de manifiesto por ejemplo, en la disminución de la capa freática. Este tipo de "Huella Hídrica" debe reducirse, pero puede ocurrir que sea a costa del empleo regional, efecto no deseado. La "Huella Hídrica" suele ser especialmente alta por el consumo de agua en la agricultura, que en muchos países es un sector importante de empleo.

Por último, la "Huella Hídrica" gris puede afectar a la salud humana, tanto en el punto de eliminación de residuos como aguas abajo.

\section{g. Costes Económicos.}

Una determinada "Huella Hídrica" siempre puede estar asociada con la creación de un determinado valor económico. Por ejemplo, el agua dulce puede ser considerada como un factor de producción. Idealmente, el agua dulce se utiliza de manera que cree el más alto nivel de bienestar, entendiendo el bienestar en un sentido amplio e incluyendo cualquier valor que la sociedad considere pertinente. Sin embargo, en la práctica solo pocas de las condiciones requeridas para el uso eficiente del agua se cumplen.

Los costes económicos de la "Huella Hídrica" en el presente estudio, se han vinculado con los costes monetarios de producción, distribución y consumo de los bienes y servicios que se generan en cada uno de los sectores y subsectores analizados 
(primario: agricultura, ganadería, silvicultura y pesca; secundario: sector industrial y sector de la construcción; y terciario; sector servicios y doméstico).

Generalmente, el abastecimiento de agua está altamente subsidiado, y en ocasiones no es asignada a los fines que crean el mayor beneficio posible a la sociedad y, la escasez de agua, la contaminación y los costes externos del abastecimiento de agua generalmente no se traducen en un coste real para el consumidor. Como consecuencia, los patrones de consumo están, en general, muy lejos del óptimo económico. El bienestar perdido de esta manera es lo que se puede considerar como el impacto económico (negativo) de la "Huella Hídrica".

Entre las razones por las cuales las condiciones para el uso eficiente del agua no se cumplen, destacan dos:

- Debido al carácter público del agua y la ausencia física de la propiedad privada, no existe un mercado que establezca un precio de agua que se base en la oferta y la demanda, y que refleje su escasez.

- En parte como resultado de la anterior, los usuarios suelen pagar un precio por el agua dulce que está muy por debajo de su valor económico real.

La mayoría de los gobiernos subsidian el suministro de agua a gran escala mediante la inversión en infraestructura como presas, canales, purificación de agua, sistemas de distribución y tratamiento de aguas residuales. Estos costes generalmente no se cobran a los consumidores, y como resultado, existe un insuficiente interés comercial por parte de los consumidores para ahorrar agua.

Además, la escasez de agua por lo general no se traduce como un componente adicional del precio de los bienes y servicios que se producen con el agua, como sucede de forma natural en el caso de los bienes privados.

Finalmente, los consumidores, por lo general, no pagan por los impactos negativos que causan en las personas o en los ecosistemas aguas abajo. Por tanto, las entradas de agua no forman un componente importante del precio total, e inclusive de los productos que más consumen agua. En definitiva, la producción de bienes no es, o no está suficientemente, regulado por la escasez de agua.

El impacto económico de la "Huella Hídrica" está relacionado de alguna manera con la ineficiencia en el uso del agua. Se pueden distinguir tres niveles en los que se puede considerar la eficiencia del uso del agua: local, cuenca hidrográfica y global (Hoekstra y Hung, 2002, 2005).

A nivel local, o del consumidor, la pregunta es si se pueden utilizar menos recursos hídricos para producir el mismo bien o servicio y lograr el mismo beneficio. La cuestión está en la cantidad de bienes producidos por unidad de agua. En la agricultura, la pregunta es: ¿podemos pedir "más por cada gota". La eficiencia del consumo local de agua en ocasiones se denomina "eficiencia productiva", y se puede expresar en términos de unidad de producto por unidad de agua, por ejemplo en t m-3. Ésta eficiencia se puede incentivar mediante el impulso de las tecnologías de ahorro de agua, como son los precios de tarificación basados en el coste marginal total, subsidiando una mejor tecnología, mayores impuestos a las tecnologías que desperdician agua, y/o la concientización de los consumidores sobre el valor del ahorro de agua. 
A nivel de cuenca hidrográfica o de zona de captación, la pregunta es cómo los recursos hídricos disponibles son asignados a los diferentes usos. Para ello es necesario conocer si se puede pedir un mayor "valor por gota". La eficiencia en el consumo eficiente del agua a este nivel también se la denomina "asignación de eficiencia", y se expresa en términos de valor monetario obtenido por unidad de agua, por ejemplo en euro m-3. Este tipo de eficiencia se puede mejorar mediante la reasignación de agua a las zonas y los propósitos que generan el mayor beneficio marginal.

Finalmente, a un nivel superior al de cuenca hidrográfica, es importante preguntarse qué regiones del mundo tienen una ventaja comparativa en la producción de bienes intensivos en agua y qué regiones tienen una desventaja comparativa. La "eficiencia global de uso del agua" se puede incrementar si los países utilizan sus ventajas y desventajas comparativas para alentar o desalentar a determinados tipos de producción (Sotelo et alii, 2010). Los factores que influyen en que un país tenga una ventaja comparativa o una desventaja en la producción de un determinado producto intensivo en agua son:

- el clima regional,

- el grado de escasez de agua regional,

- la disponibilidad y la utilización real de tecnologías hídricas,

- el suelo,

- la productividad laboral, entre otros.

g.1. Coste de capital correspondiente de las inversiones: recogen la depreciación económica de las inversiones de las infraestructuras en los diferentes "Sistemas de Explotación" de gestión de la oferta de bienes y servicios que configuran la "Huella Hídrica". Por ejemplo, empresas como las piscifactorías, las centrales hidroeléctricas, las fábricas de conservas, los hoteles y restaurantes o, grandes obras de ingeniería para la obtención de recursos hídricos como embalses, presas, depuradoras.

g.2. Costes directos de producción: recogen los costes directamente asociados a la operación y mantenimiento de las infraestructuras específicas que regulan o transportan agua a las diferentes unidades de demanda dentro de cada Sistema de Explotación. En esta categoría se incluyen los costes de mano de obra, aprovisionamientos, mantenimiento y conservación. En general, todos los comprendidos para el funcionamiento y la conservación de las infraestructuras.

g.3. Costes indirectos: recoge los costes generales de administración de los organismos públicos y privados. Dichos costes generales se imputan en función de criterios de reparto homogéneos entre todas las infraestructuras de los diferentes sistemas de explotación para la gestión de la oferta de agua. No todos los costes generales se imputan a los servicios de explotación, ya que se considera que un porcentaje de estos costes van destinados a otras actividades competencia de las Confederaciones (Comisaría de Aguas, Administración del Dominio Público Hidráulico, aforos, etc.). 


\section{RESULTADOS FINALES DE LOS COSTES-BENEFICIOS DE LA "HUELLA HÍDRICA" EN ESPAÑA.}

En primer lugar, debemos tener en cuenta que todos los costes, económicos, ecológicos y sociales, repercuten sobre la economía general de España (y de aquellos países con los que se comercializa) con lo que generan costes monetarios directos e indirectos sobre los individuos, es decir, sobre los consumidores y productores de bienes y servicios que configuran la "Huella Hídrica". De igual modo, cada uno de los costes ambientales y económicos inciden de manera directa o indirecta sobre el conjunto de la sociedad, aumentando, no sólo el nivel económico de los individuos, familiar, consumidores, productores, empresarios, ... sino que también su calidad de vida.

En la siguiente tabla, se recogen de manera más resumida, cada uno de los costes económicos, ecológicos y sociales (atendiendo también a los costes de oportunidad) de la producción de bienes y servicios de "Huella Hídrica" en España.

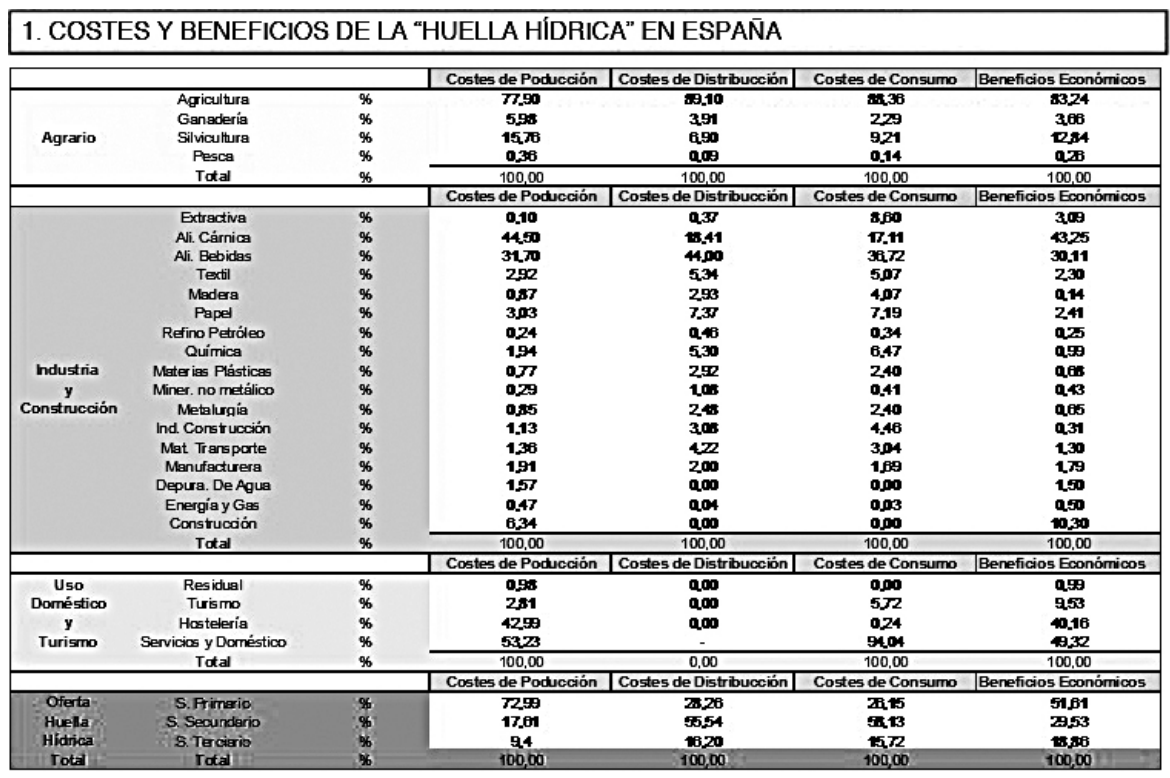

Fuente: Elaboración propia, a partir de datos del MARM (2008), INE (2009), Hoekstra, A. y Chapagain, A. (2010) 


\section{COSTES-BENEFICIOS SOCIALES Y COSTES-BENEFICIOS DE OPORTUNIDAD}

S. Agrario

$\checkmark$ Genera deseconomías de escala y Rendimientos a escala; esto repercute en la sociedad, generando ciertos desequilibrios, sobre todo en términos de poder adquisitivo.

$\checkmark$ La clara dependencia del Sector Agrario del exterior (importa más de lo que produce o exporta), respecto a la producción de bienes de "Huella Hídrica", hace que sea un sector dependiente de los subsidios estatales y de la Unión Europea y, por tanto, muy vulnerable ante los cambios políticos y económicos. En caso de que desaparezcan las ayudas, el peso de la producción de bienes agrarios caerá drásticamente, lo que repercutirá sobre el consumo de la población.

$\checkmark$ España es un país de contrastes climáticos, edáficos y de relieve, lo que genera disparidades entre los distintos territorios influyendo, en muchos casos, negativamente en la productividad del sector agrario. Con lo que repercute sobre el empleo y, por ende, sobre la renta del sector disminuyéndolos.

S. Industrial $\checkmark$ El incremento de la producción industrial puede incrementar la contaminación del recurso hídrico, del aire o del medio, incidiendo negativamente sobre la salud de la población.

$\checkmark$ De igual modo, un aumento de agua gris incrementará los precios de los bienes y servicios industriales repercutiendo sobre el precio final que pagan los consumidores. De este modo se corre el peligro de la aparición de bienes sustitutivos más baratos que hagan frente a la demanda de los consumidores aumentando la competencia y, con ello, las explotaciones.

$\checkmark$ El transporte de bienes y servicios industriales, por carretera se ha incrementado sustancialmente a los largo de estos años en España, lo que produce contaminación acústica. Esto genera una presión sobre e servicio sanitario por la repercusión negativa que tiene sobre la salud humana.

$\checkmark$ El aumento de la producción de alimentos y bebidas embasadas y congeladas, con el fin de hace de España un país dependiente de dichas industrias.

$\checkmark$ La especulación en el sector de la construcción antes, durante y después de la "crisis del ladrillo" en España, incrementó sustancialmente, no sólo la demanda, uso y empleo del recurso hídrico (sobreexplotándolo e incrementando sus costes de reposición y abastecimiento) sino que repercutió sobre los precios de dichos bienes inmuebles, sobredimensionando su coste real, con lo que se ha generado una crisis financiera familiar insostenible. Esto ha llevado a muchas familias a la quiebra.

S. Doméstico $\checkmark$ El turismo ejerce una presión muy grande sobre el territorio español. Esto hace que las demandas de recursos hídricos se disparen, sobre todo en épocas estacionales, con lo que la demanda de "Huella Hídrica" tiende a aumentar $y$, por ende, su oferta.

$\checkmark$ En el uso doméstico, la demanda de "Huella Hídrica" muestra una tendencia alcista. Con lo que la dependencia familiar y del sector servicios de estos bienes y servicios ha sido creciente en los últimos añosEsto ha repercutido negativamente sobre el consumo de las familias puesto que, al aumentar la demanda, se han incrementado los precios de consumo en más de un $2 \%$ al año (todo ello camuflado bajo el nombre de "campañas de concienciación" para la conservación de dicho bien.

S. Agrario

$\checkmark$ La inversión en la mejora de la captación y explotación del recurso hídrico, mediante el uso de una tecnología más productiva y eficaz, tales como las técnicas de cultivo bajo plástico, el regadío por goteo aspersión, evitando desperdiciar el agua verde y azul, han incrementado la productividad de ciertos cultivos en algunas regiones españolas. Esto permite, no sólo hacer frente a la demanda nacional de bienes agrarios sino que también permiten hacer frente a la demanda exterior de dichos bienes, ejerciendo un mayor peso sobre e $\mathrm{PIB}$ nacional y sobre la renta de la población (tanto en el sector agrario como en el industrial y el doméstico). Han reducido (aunque no eliminado, ya que España continúa siendo un país muy dependiente de "Huella Hídrica" agraria externa) la dependencia de nuestro país, de los bienes agrarios exteriores.

$\checkmark$ Las mejoras tecnológicas junto con la apertura al mercado exterior y las mejoras en la economía española han permitido la aparición de "denominaciones de origen" de ciertos bienes (entre ellos el agua, el vino, los quesos o el jamón). Con lo que ha producido un aumento de la riqueza real del país.

$\checkmark$ Los procesos de repoblación no sólo han favorecido a la producción silvícola, sino que han permitido la continuación mejorada del ciclo hidrológico.

S. Industrial $\checkmark$ con el fin de reducir el consumo industrial real (en términos de VAB) del recurso hídrico, se ha fomentado la inversión en $\mathrm{I}+\mathrm{D}+\mathrm{i}$. Este aumento en la inversión en Investigación, ha supuesto un reclamo de conocimiento y de riqueza cultural de la sociedad, con lo que la producción de estos bienes y servicios necesitan de una mano de obra cualificada. Esta cualificación suponen un crecimiento real de la población, lo que debería traducirse en su nivel económico.

$\checkmark$ A pesar de que la presión sobre el territorio de estas industrias es muy grande y que el crecimiento de las construcciones de zonas residenciales ha sido desmesurado, esto ha supuesto un mayor dinamismo de la población (no sólo han mejorado las comunicaciones, la alimentación y el desarrollo tecnológico) abriendo las puertas de España, (y con ello me refiero a su población) aún más hacia el exterior.

S. Doméstico

$\checkmark$ La tarificación ha permitido el control del consumo de "Huella Hídrica" evitando la sobreexplotación de las dotaciones, favoreciendo un uso racional de agua verde y azul. Con lo que la presión sobre el medio es menor incide sobre la población mediante una dotación óptima tanto en cantidad como en calidad.

$\checkmark$ El aumento de la demanda de "Huella Hidrica", proveniente del turismo y el reclamo hostelero, ha favorecido la mejora en la equidad (tanto horizontal como vertical) del reparto del recurso hídrico y de las mejoras en la calidad y bienestar de la población española

$\checkmark$ Las inversiones en depuración han permitido el uso continuado del agua gris, cada vez mayor en los grandes núcleos urbanos y periurbanos, disminuyendo así la carga sobre el agua azul y verde, y mejorando la calidad de vida de la población urbana fundamentalmente, por la reutilización de dicha agua gris, en el regado de parques, jardines, campos de golf, centros hoteleros. 


\section{COSTES -BENEFICIOS AMBIENTALES \\ S. Agrario \\ ๔ La creciente falta de autosuficiencia en el sector agrario, como es el caso de Espa ña, no sólo \\ conlleva costes económicos vinculados a la necesidad de importación de dichos bienes, sino que también \\ La falta de control de algunas prácticas agricolas, sobre todo vinculadas a explotaciones familiares minifundistas suponen un aumento de la carga de explotación y captación de recursos h ídricos de los acu iferos, disminuyendo los niveles freáticos. De igual modo, estas malas praxis de explotación generan un incremento sustancial de las aguas grises que, al no estar reguladas, acaban introduci éndose en la cadena trófica (a partir de la absorción de las plantas de dicho agua contaminada) y mezclándose con aguas de calidad al ser arrastradas hacia mares, ríos, lagos, o con aguas subterr áneas por medio de la filtración. \\ En el sector pesquero, el coste de la producción de bienes y servicios de "Huella Hídrica" recae fundamentalmente, sobre la contaminación de los mares porque se vierten aguas grises al mar, por la sobreexplotación de caladeros (en el caso de España, la regulación de la Unión Europea pone I ímites al número de capturas, pero la pesca furtiva hace mella en los caladeros) y por la cantidad de petróleo quemado que acaba entrando en la cadena trófica, generando as i no sólo costes ambientales sino que también social. \\ La fuerte dependencia del sector primario de las importaciones de bienes y servicios agrarios (agrarios, ganaderos, pesqueros y silv ícolas) ha generado externalidades negativas en algunos de los países de los que se importan las materias primas, degradando, contaminando y gene rando pobreza. \\ S. Industrial \\ La mejora en la tecnolog la y el aumento de las ya mencionadas inversiones en $1+D+i$, han favorecido un aumento sustancial del $n$ úmero total de industrias en nuestro país. Esto, lejos de disminuir las emisiones de gases contaminantes, han producido un incremento de las mimas, junto con un aumento de los costes ambientales producidos por la contaminaci ón acústica y visual de las mismas, deteriorando el territorio y sus paisajes. \\ DDe igual modo, el crecimiento paulatino de las construcciones de nuevas viviendas (en muchos casos contra la normativa legal vigente) han supuesto una presión real sobre el medio, depreciando terrenos y minusvalorando paisajes de alto valor. \\ S. Doméstico \\ $\varangle$ El aumento potencial de la demanda de "Huella $\mathrm{H}$ idrica" en el sector doméstico ha producido en España numerosas externalidades negativas, como la sobreexplotación de recursos hídricos (en los embalses), la depuración de cuantiosas masas de agua que han incrementado porcentualmente, el volumen total de emisiones de gases contaminantes a la atmósfera (lo que ha supuesto un coste adicional en servicios sanitarios), o han fomentado la aparición de un "ciclo de contaminaci ón en cadena" en la que todo el agua gris generada en una determinada área urbana repercute en los dem ás sectores económicos. Parte de esa agua gris, es absorbida por el subsuelo, contaminando las aguas subterráneas que llegan hasta los cultivos y pastos cercanos, entrando as i en la cadena trófica. \\ ADe igual modo ha ocurrido y ocurre con el turismo, no sólo de sol y playa, sino que tambi én con el turismo cultural, urbano y rural \\ S. Agrario \\ S. Industrial \\ S. Doméstico \\ $\checkmark$ La explotación de los recursos h ídricos, supone una regeneraci ón constante del ciclo hidrol ógico. \& Con los aumentos progresivos de bienes y servicios de "Huella $\mathrm{H}$ idrica" agrarios se ha fomentado la concienciación social por la protección ambiental del medio, con lo que las medidas llevada a cabo por e gobierno nacional y de la Unión Europea ha favorecido la conservación de reservas de agua marina, de los caladeros, de los pastos y cultivos, ... generando as i un control real (aunque limitado, como hemos visto) de las extracciones, captaciones, usos y vertidos, de una determinada explotación. De igual modo ha ocurrido y ocurre en los otros dos sectores econ ómicos, secundario y terciario. \\ Ela concienciaci ón por la escasez del recurso hídrico y por la protección del Medio Ambiente, ha supuesto también la limpieza de ríos, lagos, embalses, prados, campos y ciudades}

Es de esta forma como tras el estudio de los modelos coste-beneficio y coste-eficiencia de la Huella Hídrica española, a continuación pasamos a estudiar el precio de la susodicha "Huella". De esta forma, nos encontramos con que el objetivo principal de un sistema de precios es retribuir a los factores de producción que han participado en la producción y el intercambio de bienes y servicios de un mercado. El precio es la guía de la escasez relativa de los bienes y factores productivos en una economía, supone la valoración cuantitativa de los esfuerzos en la realización de las actividades económicas. El precio es reconocido como uno de los instrumentos económicos más recomendables para la mejora de la eficiencia en la gestión del agua, tanto en los países ricos como en los países en vías de desarrollo. 
Como instrumento de planificación, la política de precios debe basarse en una serie de principios formulados por diversos organismos internacionales (Comisión Europea, OCDE, ONU, etc.). Estos principios han sufrido una evolución conforme las demandas sociales evolucionaban, a la par que se modificaban las necesidades de los servicios.

\section{A LA MANERA DE CONCLUSIONES}

En la comentada y citada en nuestro estudio, Directiva Marco del Agua (Comisión Europea, 2000) se puede considerar que las políticas de precios para lograr los objetivos medioambientales y de eficiencia económica han de basarse en los siguientes principios y proposiciones: a) La aplicación del principio de recuperación de los costes. Este principio no es aplicable de manera absoluta, ya que la propia DMA establece que los Estados miembros podrán tener en cuenta los efectos sociales, medioambientales y económicos de la recuperación y las condiciones geográficas y climáticas de la región o regiones afectadas. b) La aplicación de estructuras de tarificación incentivadoras del uso eficiente del agua y la eficacia ambiental. Uno de los grandes pilares de la política del agua derivada de la implantación de la DMA es introducir adecuados incentivos para el uso eficiente y contribuir al cumplimiento de los objetivos ambientales. En este sentido, el análisis de la demanda de agua, su elasticidad, los precios que reflejen la escasez del recurso y la disposición a pagar por parte de los usuarios cobran especial relevancia, sobre todo cuando se estudia la "Huella Hídrica" de un territorio, como el español. c) Evaluación de los costes ambientales y, procurar, una internalización de dichos costes en los precios aplicados a los distintos usuarios. Esto conlleva políticas de precios que internalicen las externalidades en las decisiones de los productores y consumidores y con ello se procure la sostenibilidad en el uso de los recursos. d) Aplicación del principio de transparencia y participación de los usuarios en la fijación de los precios. Proceso que debe contar con la información adecuada ya que a menudo estos servicios se prestan en régimen de monopolio y la participación de los usuarios/consumidores para la elaboración y aceptación de una política de precios clara y adecuada a los objetivos pretendidos. e) Consideraciones de los aspectos sociales y su impacto en las políticas de precios del agua. Los objetivos sociales pueden integrarse en las políticas de tarificación y otras medidas complementarias para el cumplimiento de todos ellos. Sin embargo, las políticas sociales en este ámbito tienen un papel muy limitado. El nexo común de todos los principios postulados por los organismos internacionales se sintetizan en el cumplimiento de los principios de eficiencia y equidad. Eficiencia en la recaudación, el uso de los recursos hídricos y en la asignación. Equidad, como componente social de los precios de servicios básicos.

\section{BIBLIOGRAFÍA}

COMUNIDAD EUROPEA (2007). "Análisis Coste-Beneficio de la Directiva Marco del Agua".

FARINÓS-DASÍ, J., ROMERO-GONZÁLEZ, J. (2008). La gobernanza como método para encarar los nuevos grandes retos territoriales y urbanos. Boletín de la Asociación de Geógrafos Españoles, 46: 5-9. 
GERBENS-LEENES, P.W., HOEKSTRA, A.Y. AND VAN DER MEER. TH. (2009a) The water footprint of energy from biomass: A quantitative assessment and consequences of an increasing share of bio-energy in energy supply, Ecological Economics 68(4): 1052-1060.

GARRIDO, A., LLAMAS, M.R., VARELA-ORTEGA, C., NOVO, P., RODRÍGUEZ-CASADO, R. AND ALDAYA, M.M. (2009) Water footprint and virtual water trade in Spain, Springer, New York, USA.

HÉRNANDEZ-SANCHO, F., MOLINOS-SENANTE, M. y SALA-GARRIDO, R. (2010). "Estudio de viabilidad económica para el tratamiento de Aguas residuales a través de un análisis coste beneficio". Revista Electrónica de Comunicaciones y Trabajos de ASEPUMA. Pág. 1-25

HOEKSTRA, A., ALDAYA, M., MEKONNEN, M. Y CHAPAGAIN, A.K. (2009). Water footprints manual. Network. Enschede, Netherlands.

HOEKSTRA, A. Y., CHAPAGAIN, A. K., ALDAYA, M. M. AND MEKONNEN, M.M. (2011) "The water footprint assessment manual: setting the global standard, Earthscan, London.

INE (2007): Encuesta sobre el Agua 2005.

INE: Banco de Batos.

INM y OECC (2007): Generación de escenarios regionalizados de cambio climático en España. Primera Fase. 145 p.

INM (2009). Series mensuales de evapotranspiración potencial y precipitación para los puntos registrados de la España Peninsular. Años 1996-2009. Instituto Nacional de Meteorología. Ministerio de Medio Ambiente.

LLAMAS, M. R. (1992): “A àgua - escassez ou mau uso?” Coloquio/Ciencias. Revista de Cultura Científica. Fundaçao Calouste Gulbenkian - Lisboa, Vol. 4, núm. 12

LLAMAS, M.R., ALDAYA, M.M., GARRIDO, A., LÓPEZ-GUNN, E. (2008). Soluciones para la escasez delagua en Españay su aplicación a otras regiones. Revista de la Real Academia de Ciencias Exactas, Físicas y Naturales (España), 102(2): 1-14.

MA, J., HOEKSTRA, A.Y., WANG, H., CHAPAGAIN, A.K. AND WANG, D. (2006) Virtual versus real water transfers within China, Phil. Trans. R. Soc. Lond. B. 361 (1469): 835-842.

MAESTU, J. Y VILLAR,A. (2006): "El sector de los servicios del agua en España: "Recuperación de costes y perspectivas financieras". Revista Ambienta (Octubre, 2006). MIMAM. Madrid.

MAESTU, J y DOMINGO,L (2008). "Análisis coste-eficacia para la consecución de objetivos ambientales en masas de agua". Ministerio de Medio Ambiente. MIMAM. Madrid.

MMA (2007) El agua en la economía española: Situación y perspectivas. Informe integrado del análisis económico de los usos del agua. Artículo 5 y Anejos II y III de la Directiva Marco del Agua. Ministerio de Medio Ambiente, Madrid, España, 290 p MINISTERIO DE MEDIO AMBIENTE (2007). "El Agua en la Economía Española: Situación y Perspectivas". 
NAREDO, JM. (2007). "Costes y cuentas del agua Propuestas desde el enfoque ecointegrador". Seminario Costes y Cuentas del agua en Cataluña en relación con la Directiva Marco del Agua, Agencia Catalana del Agua, 18 y 19 de junio 2007. Cataluña.

NAREDO, J.M. Y ESTEVAN, A. (2006) "Indicios de sobrevaloración de las disponibilidades de agua estimadas por la planificación hidrológica (que deberían de ser objeto de análisis prioritarios para atender a las exigencias del artículo 5 de la DMA)" Nota presentada en Bruselas, el 9 de noviembre de 2006, a la Min istra de Medio Ambiente y a algunos funcionarios de la Comisión de la UE (disponible en la Web de la Fundación Nueva Cultura del Agua).

RODRÍGUEZ CASADO, R., GARRIDO, A., LLAMAS, M.R. AND VARELAORTEGA, C. (2008) La huella hidrológica de la agricultura española. Papeles de Agua Virtual n. ${ }^{\circ}$ 2, Fundación Marcelino Botín, Santander, ISBN 978-84-9665525-6, $38 \mathrm{pp}$

SOTELO, J.A. (2009). "Las lógicas ilógicas del agua". Tribuna Complutense. pp.4.

SOTELO, J.A. et alii. (2010). "La Huella Hídrica española en el contexto del cambio ambiental". Fundación Mapfre. Madrid. 218pp.

SOTELO PÉREZ, M (2010) "la Huella Hídrica de España" Instituto Universitario de Ciencias Ambientales .Universidad Complutense de Madrid. Grupo de Investigación Desarrollo y Gestión Ambiental del Territorio.

VALIÑO, A. et alii (1995) "Análisis coste-beneficio. Gasto Público". The Economist: The Great Escape?. House of Debt. The Economist. 